Esta revista forma parte del acervo de la Biblioteca Jurídica Virtual del Instituto de Investigaciones Jurídicas de la UNAM

\title{
El control jurisdiccional ciudadano de los procesos electorales en México
}

\section{José Fernando Ojesto Martínez Porcayo*}

\section{Sumario:}

I. Introducción

II. Iusnaturalismo renovado

III. La reforma constitucional al artículo primero (10 de junio de 2011)

IV. El bloque de constitucionalidad y los derechos humanos

V. Derechos político-electorales de configuración legal

VI. Tratamiento jurisprudencial de los derechos políticos

VII. El Juicio de protección de los derechos político-electorales del ciudadano (JDC), garantía de la constitucionalidad y legalidad de los actos en materia electoral

VIII. Necesidad de consagración del derecho de observación electoral en el texto constitucional

IX. La observación electoral y el sistema de nulidades en materia electoral

X. Nuevos instrumentos jurídicos para el control jurisdiccional ciudadano de los procesos electorales

XI. Fuentes consultadas

* Doctor en Derecho por la UNAM, y maestro en Ciencias Sociales por la London School of Economics and Political Science. Fue magistrado presidente de la Sala Superior del TEPJF, de 2000 a 2004; es profesor en la Facultad de Derecho y en el Posgrado de la UNAM. 
Esta revista forma parte del acervo de la Biblioteca Jurídica Virtual del Instituto de Investigaciones Jurídicas de la UNAM www.juridicas.unam.mx http://biblio.juridicas.unam.mx

\section{Resumen:}

Después de siete ciclos de observación electoral en nuestro país, en donde el acompañamiento del Programa de Naciones Unidas para el Desarrollo (PNUD) ha sido fundamental, es necesario reflexionar sobre los instrumentos jurisdiccionales con que cuentan los ciudadanos para coadyuvar en la estricta observancia de las reglas que norman los comicios federales. La participación ciudadana es indispensable, no sólo para fortalecer el sistema electoral, sino además, para afianzar la credibilidad en las instituciones y procedimientos electorales. La hipótesis de este ensayo es que los derechos político-electorales, entre ellos el de la observación electoral, son derechos fundamentales que deben tener una consagración constitucional y contar con los medios legales para su plena efectividad.

Palabras clave: bloque de constitucionalidad, derechos humanos, derechos político-electorales, derecho de observación electoral, constitucionalidad, legalidad. 
El presente trabajo es una reflexión desde la academia, respecto al reciente proceso electoral mexicano de 2012 para renovar al titular del Poder Ejecutivo y el rol jurídico que la Constitución y la ley otorgan a la observación ciudadana. Es indudable que en este ejercicio prevalecerá mi experiencia como juez electoral que desempeñé por cerca de veinte años.

Un análisis del sistema político nacional requiere, aunque sea rudimentariamente, de una explicación sobre los fundamentos filosóficos y teóricos en que descansa la Constitución.

En materia jurídica existen tres posturas filosóficas, claramente diferenciadas, que pretenden establecer la esencia del derecho, en este caso constitucional, para de ahí desarrollar las teorías que expliquen el qué, el por qué y el para qué de este conjunto normativo, para la convivencia pacífica y armónica de los seres humanos. ${ }^{1}$

La escuela filosófica del derecho natural tiene como característica la de afirmar la existencia del dualismo normativo, es decir, que existen dos órdenes jurídicos: uno supraordenado a otro, cuya validez depende de su concordancia con el superior.

El orden superior o "natural" tiene su fundamento o validez (dependiendo de la inclinación filosófica del pensador) en la voluntad divina (iusnaturalismo teológico), por lo que los derechos de las personas derivan de la categoría de hijos de Dios, dotados por tanto de una dignidad no susceptible de ser variada por el legislador (ya sea rey, asamblea, parlamento, etcétera); en cambio, nuestra naturaleza racional permite que nos propongamos los fines y medios para alcanzarlos distinguiendo entre lo que es bueno y lo que es malo (iusrealismo); mientras nuestra naturaleza social, permite observar la conducta del hombre y lo que es válido en sociedad, de manera que es posible descubrir los derechos universales opuestos a las prácticas específicas o singulares de una determinada comunidad (Grocio, Vitoria). Respecto a la naturaleza de las cosas (Maihofer), es decir de las situaciones vitales de comunicación, de los roles que desempeñamos en nuestras

1 García Máynez, Eduardo, Positivismo jurídico, Realismo Sociológico y Iusnaturalismo, Textos Universitarios, México, UNAM, 1977. 
Esta revista forma parte del acervo de la Biblioteca Jurídica Virtual del Instituto de Investigaciones Jurídicas de la UNAM

vidas, es posible derivar lo que debemos hacer en cada caso, esto es, el derecho natural inmerso en el deber ser concreto. Existen más teorías y corrientes filosóficas del derecho que establecen la existencia de los derechos del hombre, así, quien ostente el poder en una sociedad no puede disminuirlos, pero sí promover su reconocimiento y protección.

La escuela del derecho natural que tiene su origen en el pensamiento griego (Sócrates y Platón), se consolida con los estoicos y pasa reforzada con el cristianismo al derecho romano, logrando sus más altas expresiones en la Edad Media a través de la patrística (Santo Tomás, San Agustín), que tuvo siempre una función más bien teórica que práctica. ${ }^{2}$ El desarrollo de los principios de justicia y de sus máximas, servían para enjuiciar las leyes y actos de los monarcas y de sus operadores jurídicos, sus resultados se evidenciaban en el campo moral y permitían a los estudiosos del derecho condenar, reprochar o aprobar los actos del poder, pero sin vinculación jurídica real.

El iuspositivismo como tendencia filosófica alcanza su consagración con los movimientos de la gloriosa Revolución inglesa, la independencia norteamericana, la Revolución francesa y el liberalismo español que culminan con el reconocimiento de los derechos inalienables del hombre a través de su consagración en los textos jurídicos, sobre todo constitucionales y en su protección jurídica.

La única fuente del derecho es la ley (monismo jurídico). El Estado crea la ley por medio de los poderes constituidos y a través de procedimientos formales, a la vez que se compromete a que sea observada (monopolio de la fuerza), pero también sirve para limitar su poder, y adquiere su legitimidad a través de la legalidad.

De acuerdo con esta posición, el Estado constitucional moderno se caracteriza por tener una división de poderes (a efecto de evitar su concentración y por ende su abuso), el reconocimiento de la soberanía popular y la existencia de derechos subjetivos públicos del hombre y del ciudadano, tutelados o protegidos de los abusos del poder por medios jurídicos.

Las características del iuspositivismo son:

1) Monísmo. Sólo es derecho el creado e impuesto por los órganos estatales (niegan que el derecho natural sea verdaderamente derecho).

2 Bodenheimer, Edgar, Teoría del derecho, México, Fondo de Cultura Económica, 1976. 
2) El derecho es un sistema que determina la validez y aplicabilidad de las normas, sus reglas de interpretación y aplicación que hacen a las mismas coherentes, colma sus vacíos con lo que se hace completo y se eliminan las antinomias (legislador racional).

3) Monopolio estatal. El derecho positivo es un sistema de normas instituido por un poder social, supremo, que ejerce el monopolio de los medios de coacción.

4) El sistema es unidad. El derecho sólo puede ser creado a través de las fuentes formales, quien aplica e interpreta las leyes no puede resolver sino acudiendo a tales fuentes y a sus principios y reglas.

5) La obligatoriedad de las normas jurídicas no depende de la opinión de los destinatarios sobre la bondad o justicia intrínseca de sus preceptos. ${ }^{3}$

Los excesos del nazismo principalmente, hicieron pensar, después de la Segunda Guerra Mundial, que había que tener sistemas jurídicos que impidieran que los propios poderes legislativos tuvieran la facultad de alterar el respeto a los derechos fundamentales.

Sobre todo en Europa, se planteó la necesidad de contar con órganos de protección de los derechos fundamentales contenidos no sólo en las Constituciones, sino también los reconocidos en instrumentos internacionales. Estos denominados "órganos de control constitucional" o "tribunales constitucionales" fueron implementándose gradualmente desde la Constitución austriaca (impulsada por Hans Kelsen, principal representante de la escuela vienesa).

Finalmente la posición filosófica conocida como iusrealismo sociológico considera que la validez del derecho debe encontrarse en la realidad social, en las formas en cómo las personas se vinculan con la ley y cumplen con ella sin importar cuáles son sus fuentes, si su contenido es justo o si su proceso de producción se ajustó a las formas legales establecidas. Lo importante para esta escuela es que la gente lo considere obligatorio y que por lo tanto su imposición sea legítima. Esta posición asigna a la tarea de los jueces una gran relevancia al grado de que Alf Ross considera que la vigencia de las normas radica fundamentalmente en el reconocimiento y aplicación judicial del derecho.

3 Scarpelli, Uberto, Cos 'é il positivismo giuridico, Milano, 1965, cit. en García Máynez, op. cit., p. 42. 
Esta revista forma parte del acervo de la Biblioteca Jurídica Virtual del Instituto de Investigaciones Jurídicas de la UNAM

Una norma es vigente cuando el juez la usa para justificar su decisión (cualesquiera sean los motivos que lo impulsan a tomarla). ${ }^{4}$

Esta breve reflexión resulta relevante para entender la filosofía que subyace en una Constitución y los derechos contenidos en ella. Con este análisis podremos responder a las siguientes interrogantes: ¿los derechos fundamentales son una creación estatal, es decir, encuentran su fuente o fundamento en la voluntad del Estado representado por la asamblea legislativa (iuspositivismo)?, ¿ encuentran fundamento en su contenido de justicia, por su respeto a derechos preexistentes inherentes a la calidad de ser humano (iusnaturalismo)?, o ¿encuentran su razón de ser en la realidad y en la vinculación que las personas tienen con sus preceptos (iusrealismo sociológico)?

\section{Iusnaturalismo renovado}

Después de su olvido por más de ciento cincuenta años (aunque en ciertos círculos religiosos, especialmente católicos, nunca se abandonó), el "iusnaturalismo positivizado" ha triunfado tanto en la reflexión como en la práctica jurídica actual; desde la reflexión, con la filosofía del derecho o metajurídica, cuando se abordan los principios y valores a los que el derecho concreto (positivo) debería aspirar o que el "deber ser puro" sea reivindicado.

Bajo nuevas tipologías como "neocontractualistas", "neokantianos", "neoconstitucionalistas, "garantistas", "antiformalistas", etcétera, el pensamiento jurídico actual considera que existe un núcleo "duro" o intocable, una esfera de lo indecidible, un bloque de constitucionalidad que se encuentra protegido aún en contra de las intervenciones del poder revisor de la Constitución. La premisa mayor es que si bien el "estatus" jurídico fundamental de las personas, no puede disminuirse, pero sí es susceptible de ampliación, extensión o adición. Los derechos "fundamentales", "humanos", "subjetivos públicos" o "garantías individuales", siempre deben potenciarse y expandirse a lo máximo, y sobre todo, hacerse efectivos, operantes en la realidad, o como decía Luis Recasens Siches, convertirse en "vida humana objetivada".

${ }^{4}$ Ross, Alf, El derecho y la justicia, London, Stevens and Sons Ltd., 1958, p. 11, cit. en García Máynez, op. cit., pp. 75 y ss.

5 Recasens Siches, Luis, Introducción al estudio del derecho, México, Porrúa, 1974, pp. 25-28. 
El insigne procesalista italiano Mauro Cappelleti ${ }^{6}$ ha documentado la evolución del movimiento de la protección jurídica de los derechos humanos, en el siglo pasado en Norteamérica con el judicial review, y en el resto de América y Europa a través del surgimiento de órganos de control de la Constitución o tribunales constitucionales, en este tenor, se aboga por una nueva forma de interpretación judicial en la que la Constitución garantice la vigencia y eficacia de los derechos individuales, sociales y económicos consagrados en los textos fundamentales de los Estados constitucionales.

Otro tema paralelo a la consagración y protección de los derechos fundamentales en los textos constitucionales y en los pactos y declaraciones internacionales, es el reconocimiento de los derechos políticos y el derecho a un sistema democrático, con la misma dignidad y categoría que las libertades primarias o derechos fundamentales de primera generación.

El paradigma jurídico moderno lo constituye el "Estado constitucional democrático de derecho", tal y como lo exigen las convenciones internacionales como la Declaración Americana de los Derechos y Deberes del Hombre - "Pacto de San José”- y la Declaración Universal de Derechos Humanos, ambas de 1948.

Actualmente el desarrollo de la democracia coincide con la extensión progresiva de los derechos políticos; encontramos por tanto, el derecho de participar mediante la elección de representantes en la formación de la voluntad colectiva, pero cada vez se exigen más instrumentos para incentivar la participación directa de los ciudadanos.

Académicamente me defino como un contractualista, es decir, acepto la idea de que la libertad sólo puede ser jurídica y que deriva de un acto voluntario, un pacto social, en donde los individuos acuerdan sobre las reglas a que deben someterse con el objeto de convivir en paz y lograr su propia superación; neokantiano, toda vez que considero que la norma jurídica debe tener su origen en la voluntad libre y autónoma y además debe ser aceptada universalmente de tal forma que represente un imperativo categórico, y democrático, considerando que los derechos políticos tanto de primera como de segunda generación ${ }^{7}$ son derechos fundamentales del mismo rango y dignidad

\footnotetext{
6 Cappelleti, Mauro, La justicia constitucional (estudios de derecho comparado), México, UNAM, Facultad de Derecho, 1987.

${ }^{7}$ La primera generación de derechos políticos son: libertad de expresión, derecho de
} 
Esta revista forma parte del acervo de la Biblioteca Jurídica Virtual del Instituto de Investigaciones Jurídicas de la UNAM

que las libertades básicas, y que si bien no son jerárquicamente superiores, sí son anteriores, pues como dice Sartori, ${ }^{8}$ son "libertades de", que permiten el ejercicio y disfrute de las "libertades para", por lo que no pueden ser restringidas en beneficio de otros derechos y requieren mecanismos de defensa de igual efectividad que las otras libertades.

Como señala Felipe de la Mata "con la progresiva constitucionalización, los derechos políticos fueron configurándose como una categoría de los derechos humanos, hecho reforzado por su inclusión en los diversos tratados y convenciones". ${ }^{9}$

Este reconocimiento de los derechos de las personas, que en filosofía jurídica no es más que la aceptación de la postura iusnaturalista —es decir, "en lugar del otorgamiento de garantías individuales-, invierte la lógica a partir de que los derechos son concebidos, los cuales dejan de ser el producto de una concesión del Estado y, en su lugar, constituyen el ámbito de libertad inherente a los seres humanos y deben garantizarse por el poder público para lograr coherencia y armonía con lo dispuesto en los instrumentos internacionales de la materia, y que forman parte de las normas fundamentales del país.

Esta nueva teoría y práctica del derecho ha impactado también el terreno de la interpretación jurídica y del papel preponderante que corresponde a los jueces. Ahora existen más principios que reglas y por lo tanto más ponderación que subsunción (postura clásica del positivismo); omnipresencia de la Constitución en todas las áreas jurídicas y en todos los conflictos relevantes, en lugar de espacios exentos a favor de la función legislativa; superioridad judicial en lugar de la autonomía del legislador ordinario, y coexistencia de una pluralidad de valores en lugar de homogeneidad ideológica. ${ }^{10}$

réplica, libertad de asociación o reunión, de imprenta, tolerancia o libertad de culto, no discriminación, educación.

Los derechos políticos de segunda generación son aquellos sin los cuales no se puede aducir que hay bases firmes y estructura de auténtico Estado de Derecho, sustentado en la legalidad que haga posible el ejercicio de todos los demás derechos, v. gr. Votar, ser votado, asociarse y afiliarse en partidos políticos, igualdad de géneros, observación electoral, etcétera.

8 Sartori, Giovanni, ¿Qué es la Democracia?, 2a. ed., México, Patria, 1997.

9 Mata, Felipe de la, Manual del sistema de protección de los derechos político-electorales en México, México, Porrúa, 2012, pp. 3 y 7.

${ }^{10}$ Gil Domínguez, Andrés, Neoconstitucionalismo y derechos colectivos, Buenos Aires, Ediar, 2005, pp. 13 y 14. 
Esta revista forma parte del acervo de la Biblioteca Jurídica Virtual del Instituto de Investigaciones Jurídicas de la UNAM

Bajo esta posición jurídica (iusnaturalismo racional renovado) procederé a hacer el análisis dogmático de los derechos políticos y especialmente el de observación electoral a la luz del ordenamiento constitucional y legal mexicano.

\section{La reforma constitucional al artículo primero (10 de junio de 2011)}

La reforma constitucional publicada en el Diario Oficial de la Federación (DOF) el 10 de junio de 2011, transforma de manera sustancial la concepción jurídica sobre los derechos humanos, su protección jurídica y el control de la constitucionalidad.

En su artículo 1o., la Constitución sustituye el término "garantías individuales" por el de "derechos humanos" decretando que toda persona goza de los derechos reconocidos por ella y los tratados internacionales de derechos humanos ratificados por México. Con esta reforma no existe duda de que los derechos políticos forman parte de los derechos humanos, superando la vieja tesis jurisprudencial que los excluía por considerarlos una categoría aparte perteneciente exclusivamente al "estatus" de los ciudadanos, y por ende no aptos de ser protegidos por el juicio de amparo. ${ }^{11}$

Esta reforma y la jurisprudencia emitida por la Suprema Corte de Justicia de la Nación (SCJN), consultable en "Varios 912/2010, publicado en el DOF el 4 de octubre de 2011" y conocida como el "Caso Radilla", ha operado un cambio en el control de la constitucionalidad, que deja de ser concentrado (únicamente lo ejercía el Poder Judicial de la Federación) para convertirse en "difuso" correspondiéndole a todos los jueces, tanto locales como federales, la expulsión de normas que contravengan a la Constitución.

Asimismo, como lo sostuvimos anteriormente, se ha operado otro cambio en la impartición de justicia, el llamado "control de la convencionalidad". Ahora se ha superado la tesis de que los tratados internacionales tenían una menor jerarquía que la Constitución, por lo que

11 Derechos políticos IMPROCEDENCIA. LA VIOLACIÓN DE LOS DERECHOS POLÍtiCOS NO DA LUGAR AL JUICIO DE AMPARO, PORQUE NO SE TRATA DE GARANTÍAS INDIVIDUALES, Tesis 219, apéndice 1917-1995, Quinta Época, t. VI, primera parte, pleno, p. 149. 
Esta revista forma parte del acervo de la Biblioteca Jurídica Virtual del Instituto de Investigaciones Jurídicas de la UNAM

al existir contradicciones entre estos y aquella, prevalecía la norma constitucional por encima de todo.

Actualmente los tratados internacionales forman parte de la Constitución y todos los jueces del país deben dejar sin efectos jurídicos, es decir, expulsar del sistema normativo, aquellas leyes y artículos que los contravengan, especialmente los relacionados con los derechos humanos.

Tan importantes cambios en el sistema constitucional mexicano, implican una nueva visión en la impartición de justicia. Se requiere que la actividad de los jueces no sea sólo formal, pasiva y confinada a la interpretación gramatical del texto, sino que se transforme en una actividad garantista, expansiva y progresista de los contenidos de la Constitución y de los derechos fundamentales consagrados en ella y en los tratados internacionales.

El juzgador necesita nuevos instrumentos argumentativos que le permitan ponderar para respetar los valores constitucionales. El juez debe estar preparado para hacer interpretaciones, no sólo intrasistemáticas sino también metajurídicas de los principios máximos contenidos en el orden jurídico nacional e internacional, lo que implica racionalizar, bajo criterios de la mayor objetividad jurídica, el valor a tutelar y después argumentar con rigor técnico, claridad y transparencia, a manera de la creación de imperativos categóricos que convenzan a los justiciables. El juez ya no debe ser el mecánico aplicador de las reglas sino su verdadero intérprete y operador.

Finalmente, la Constitución exige a los jueces la aplicación permanente del principio pro homine o pro personae, es decir, una labor hermenéutica con la perspectiva humana más amplia, lo más favorable a la persona.

Los derechos humanos deben potenciarse, expandirse, nunca restringirse.

\section{El bloque de constitucionalidad y los derechos humanos}

En el artículo 35 de la Constitución Política de los Estados Unidos Mexicanos (CPEUM) se establece el catálogo de los derechos que pertenecen al ciudadano. Sus prerrogativas son: 
1) Votar en las elecciones populares.

2) Poder ser votado para todos los cargos de elección popular, teniendo las calidades que establezca la ley; que sean registrados por un partido político o de manera independiente por sí mismos (aún no ha sido expedida la ley reglamentaria).

3) Poder ser nombrado para cualquier cargo o comisión del servicio público, teniendo las calidades legales.

4) Iniciar leyes cuando menos por el $0.13 \%$ de la lista nominal de electores (la ley reglamentaria no ha sido expedida).

5) Votar en las consultas populares sobre temas de trascendencia nacional.

6) Convocar a consultas populares (al menos $2 \%$ de los inscritos en la lista nominal de electores, en este caso la petición debe ser aprobada por cada cámara del Congreso o cuando menos el $40 \%$ de los ciudadanos inscritos en la lista. La petición será vinculatoria para el ejecutivo y legislativo federales.

7) Asociarse individual y libremente para tomar parte en forma pacífica en los asuntos políticos del país.

8) Tomar las armas en el ejército o guardia nacional para la defensa de la República y de sus instituciones en los términos que prescriban las leyes.

9) Ejercer en toda clase de negocios el derecho de petición.

De estos derechos, considero que sólo los comprendidos en los numerales 1, 2, 4, 5, 6, 7 y 9 son políticos, los demás son únicamente ciudadanos.

Más adelante el propio texto constitucional, en los artículos 41 y 99, establece la categoría específica de los derechos político-electorales del ciudadano, definición que tiene una importancia relevante pues establece una protección jurídica o garantía diferenciada para estos, toda vez que será a través del juicio para la protección de los derechos político-electorales del ciudadano (JDC) y no del juicio de amparo (aplicable en la defensa de todos los derechos humanos), como se podrá resolver sobre su vulneración con la característica de que el juicio se sustanciará ante el Tribunal Electoral del Poder Judicial de la Federación (TEPJF). Estos derechos son: votar, ser votado, asociación en materia política y afiliación a los partidos y agrupaciones políticas.

Otros derechos fundamentales vinculados a los político-electorales son: el derecho a la información, el derecho de petición en general, 
Esta revista forma parte del acervo de la Biblioteca Jurídica Virtual del Instituto de Investigaciones Jurídicas de la UNAM

el derecho de expresión (libertad de imprenta), y cualquiera otro que se diga vulnerado cuando la materia principal que se cuestiona sea la electoral.

Pertenecen también a los derechos fundamentales conforme al artículo 1o. de la CPEUM, aquellos contenidos en los tratados internacionales, como por ejemplo, en la Convención Americana de Derechos Humanos y en el Pacto Internacional de Derechos Civiles y Políticos.

Así, el artículo 23.1 de la Convención establece que todos los ciudadanos deben gozar de los siguientes derechos y oportunidades - los que deben ser garantizados por el Estado en condiciones de igualdad-: a) participar en la dirección de los asuntos públicos, directamente o por representantes libremente elegidos; $b$ ) votar y ser elegido en elecciones periódicas, auténticas, realizadas por sufragio universal e igual y por voto secreto que garantice la libre expresión de los electores, y c) acceder a las funciones públicas de su país.

Así mismo, la Convención reconoce otros derechos políticos como el de expresión (artículo 13); el de rectificación o respuesta (artículo 14), y la libertad de asociación (artículo 16).

El Pacto reconoce el derecho al sufragio (artículo 25), etcétera. ${ }^{12}$

\section{Derechos político-electorales de configuración legal}

Aunados a los derechos político-electorales reconocidos en la CPEUM, encontramos algunos de configuración legal.

En el Código Federal de Instituciones y Procedimientos Electorales (Cofipe), tenemos los siguientes:

- Artículo 4.1: “... También es derecho de los ciudadanos y obligación para los partidos políticos la igualdad de oportunidades y la equidad entre hombres y mujeres para tener acceso a los cargos de elección popular".

- Artículo 5.4: "Es derecho exclusivo de los ciudadanos mexicanos participar como observadores de los actos de preparación y desarrollo del proceso electoral, así como de los que se llevan a

12 De la Mata, op. cit., p. 6. Para conocer el alcance y extensión que el TEPJF ha establecido sobre estos derechos, véase también pp. 49-58. 
cabo el día de la jornada electoral, en la forma y términos en que determine el Consejo General del Instituto para cada proceso electoral, de acuerdo a las bases siguientes...."

- Artículo 41: “... Acceder a la información de los partidos políticos de conformidad con las reglas previstas en este Código y las que, en lo conducente, resulten aplicables conforme al Reglamento del Instituto Federal Electoral en la materia....

En la Ley General del Sistema de Medios de Impugnación en Materia Electoral (LGSMIME), se cuenta con lo siguiente: derá:

El juicio de protección de los derechos político-electorales proce-

- Artículo 79.2 “... por quién teniendo interés jurídico, consideré que indebidamente se afecta su derecho para integrar las autoridades electorales de las entidades federativas".

\section{Tratamiento jurisprudencial de los derechos políticos}

La reforma constitucional de 2011, indudablemente requiere de un cambio en las habilidades de la judicatura del país pues:

... se convierte en una exigencia normativa expresa que los jueces decidan a la luz de los derechos fundamentales, considerando para ello los tratados internacionales. Si bien esta tarea es una obligación "persee" de quienes imparten justicia en una democracia constitucional, los cambios normativos recientes en México exigen que los jueces redimensionen el plano supranacional y su valor vinculatorio en el desempeño de la labor jurisdiccional para la protección de los derechos, en este caso, de carácter político... ${ }^{13}$

En palabras del magistrado presidente del TEPJF, Alejandro Luna Ramos:

13 Ibidem, p. XIII. 
Esta revista forma parte del acervo de la Biblioteca Jurídica Virtual del Instituto de Investigaciones Jurídicas de la UNAM

... los jueces y demás autoridades nacionales deben resolver e interpretar las normas bajo el principio "pro homine" (pro persona), buscando siempre el mayor beneficio para las personas, además de hacerlo bajo los estándares del derecho internacional. ${ }^{14}$

En la práctica jurisdiccional, esta filosofía se ha ido concretando paulatinamente; baste analizar algunas de las resoluciones de la SCJN y del TEPJF para confirmar tal afirmación.

En el expediente "Varios 912/2010", la SCJN sostuvo que:

Todas las autoridades del país, dentro del ámbito de sus competencias, se encuentran obligadas a velar por los derechos contenidos en la Constitución Federal y los tratados internacionales signados por México, adoptando la interpretación mas favorable, a pesar de las disposiciones en contrario que se encuentren en cualquier norma inferior.

La SCJN ha sostenido que todas las autoridades del país deben hacer un control de "convencionalidad" ex officio en el que se incluyan todos los derechos humanos contenidos en la Constitución federal así como en la jurisprudencia emitida por el Poder Judicial de la Federación; los derechos humanos contenidos en los tratados internacionales en los que el Estado mexicano sea parte; los criterios vinculantes de la Corte Interamericana de Derechos Humanos y los criterios orientadores de la jurisprudencia y precedentes de la citada Corte. ${ }^{15}$

La labor garantista del TEPJF es ampliamente reconocida desde su instauración en 1996. Recientemente se pueden destacar los asuntos relativos a la población indígena y sus derechos políticos (jurisprudencias 27/2011,28/2011, 15/2010 y 13/2008), sobre libertad de expresión (jurisprudencia 11/2008), a cerca de la observación electoral (jurisprudencia 25/2011), suspensión de derechos político-electorales (jurisprudencia 20/2011), etcétera.

14 Ibidem, p. XVIII.

15 Parámetro para control de Convencionalidad “Ex OfFicio" en Materia de Derechos humanos, tesis LXVIII/2011, Semanario Judicial de la Federación y su Gaceta, Décima Época, L. III, t. 1, diciembre de 2011, Pleno, p. 551. 


\section{El juicio de protección de los derechos político- electorales del ciudadano (JDC), garantía de la constitucionalidad y legalidad de los actos en materia electoral}

Es importante resaltar que desde la Constitución de 1857, México instituyó el juicio de amparo como medio de protección de las llamadas "garantías individuales", hoy derechos fundamentales. Es así que actualmente el instrumento privilegiado en la defensa de las libertades humanas sigue siendo "el juicio de garantías".

Sin embargo, este medio no operaba en materia electoral por razones históricas que no es posible analizar en este estudio, sino que es hasta 1996 (influyen las resoluciones de la Corte Interamericana de Derechos Humanos), cuando se establece el JDC determinando que el órgano jurisdiccional competente sería el TEPJF.

Desde entonces, a partir de una actividad judicial innovadora por antiformalista y garantista, el TEPJF ha logrado la potenciación, expansión y efectividad de los derechos de votar, ser votado, asociación en su modalidad de creación de partidos políticos, tanto nacionales como locales, agrupaciones políticas, del derecho de afiliación a los partidos políticos con todos los derechos inherentes, de la información sobre las actividades de los partidos políticos y la obtención de la credencial para votar con fotografía.

En palabras de De la Mata Pizaña, el JDC se ha convertido en un "amparo electoral". ${ }^{16}$

\section{Necesidad de consagración del derecho de observación electoral en el texto constitucional}

Como se afirmó anteriormente, cuando un derecho se consagra en el texto constitucional, éste deviene formalmente en "fundamental" y por lo tanto adquiere una protección y extensión privilegiada. Por lo regular adquiere el carácter de "principio".

\footnotetext{
16 Ibidem, p. 29.
} 
Esta revista forma parte del acervo de la Biblioteca Jurídica Virtual del Instituto de Investigaciones Jurídicas de la UNAM

Además, el operador jurídico, sea una autoridad jurisdiccional o administrativa, adquiere la obligación de hacer una interpretación pro homine, es decir potencializadora, extensiva y especialmente garantista para hacer efectivo y pleno el derecho estatuido.

Sin embargo, cuando el derecho se encuentra solamente consagrado en el texto legal, asume, por lo regular, el carácter de "regla", de directriz, de mandato, obligando a su aplicador o intérprete a una función, si bien importante, menos trascendente que si se tratase de un "principio", relativa a la constatación de la reunión de los elementos que permiten verificar su legalidad, es decir, su conformidad con el supuesto normativo que le da origen.

En relación con el derecho de observación electoral (DOE), su regulación en el texto secundario - el Cofipe - trae aparejada limitaciones importantes de las cuales sólo señalaré algunas.

En primer lugar, no existe base constitucional expresa que permita la observación del proceso electoral, lo que implica que su existencia, modificación y modalidades se encuentran a merced de la voluntad del legislador secundario. Si estuviera previsto en el texto constitucional su modificación requeriría de la intervención del Poder Revisor de la Constitución (aprobación por mayoría calificada de ambas cámaras y de la mayoría de las legislaturas de los estados).

Tampoco se encuentra consagrado en las declaraciones de los derechos humanos signadas por México, y por lo tanto no entran en la protección otorgada por el artículo 1o. de la Constitución, es decir, no admiten la interpretación pro homine ex officio que hemos descrito anteriormente.

Existen otras limitaciones en el texto del Cofipe que desde mi punto de vista disminuyen el valor de este derecho ciudadano: por ejemplo, que las normas no pueden ser sujetas de una "acción de inconstitucionalidad"; que las observaciones que se hagan sobre el proceso electoral no tienen efectos jurídicos, o que éstas se encuentren limitadas a las normas reglamentarias que discrecionalmente emita el Instituto Federal Electoral (IFE).

Por lo tanto, propongo que en el texto del artículo 35 de la CPEUM se agregue un inciso que establezca que es prerrogativa de los ciudadanos mexicanos el derecho de observar los procesos electorales.

Además, sería necesario hacer un agregado al artículo 41 de la propia carta magna a efecto de que se vuelva a establecer que la función electoral, si bien es una actividad estatal, requiere entre otros de la 
coadyuvancia de los ciudadanos a través de la observación electoral. Esta adición aclararía la naturaleza jurídica de este derecho, cuya teleología consiste en que el proceso electoral se realice con autenticidad y respeto absoluto a la voluntad ciudadana.

\section{La observación electoral y el sistema de nulidades en materia electoral}

La elección presidencial de 1988, despertó conciencias en gran parte de la sociedad mexicana. La exigencia de reformas al sistema político se produjeron no sólo por los partidos políticos de oposición, sino también por los grupos de intelectuales más avanzados del país, por las nacientes organizaciones no gubernamentales de la sociedad civil (ONG's) y también por el propio gobierno, el cual, encabezado por el presidente Carlos Salinas de Gortari, convocó a una reforma política incluyente y de gran envergadura.

Así en la reforma constitucional y legal de 1990 que culminó con la creación del IFE y del Tribunal Federal Electoral (Trife), se produjeron avances importantes en la calidad de las elecciones mexicanas: un órgano profesional encargado de la organización administrativa de las elecciones; un órgano jurisdiccional autónomo cuya finalidad era garantizar la legalidad de la actuación de esa autoridad administrativa; un registro de electores confiable, y una contienda más equitativa con topes de campaña y financiamiento público a partidos, entre otros logros.

El resultado fue tener en 1991 elecciones federales más transparentes que permitieron a la oposición una mayor presencia en las cámaras del Congreso de la Unión. Esta nueva y plural conformación produjo un rol más importante en el siguiente ejercicio de reformas al sistema electoral en 1993. Por primera vez, desde mi punto de vista, la agenda de la reforma política fue dictada por la oposición y no impuesta por el gobierno.

No es el tema de este trabajo analizar la reforma electoral de 1993, pero sí destacar que se fortaleció el papel de la sociedad civil en el proceso electoral al introducir en el texto del Cofipe el derecho de los ciudadanos a participar como observadores electorales, exclusiva- 
Esta revista forma parte del acervo de la Biblioteca Jurídica Virtual del Instituto de Investigaciones Jurídicas de la UNAM

mente el día de la jornada electoral, previo registro y capacitación por el IFE o quien éste estimare para tal efecto.

Una opinión personal respecto a esta "legalización" de la observación electoral nacional es, primero, que ésta sí derivó en parte de la exigencia de grupos de la sociedad civil que la venían realizando, sin bases legales, desde 1988, pero además, en segundo lugar y tal vez más importante, considero que existía un enorme interés de parte del gobierno de construir confianza en el nuevo diseño legal del sistema electoral y de la fortaleza del nuevo IFE, es decir, el fenómeno de implementación fue vertical, se auspició (hasta económicamente) desde el vértice del gobierno a la sociedad civil y no a la inversa.

Otro fenómeno que produjo la regulación legal de la observación electoral es su vinculación al día de la jornada electoral. La observación se hacía en la casilla el día de la elección; por eso las ONG’s más veteranas se han profesionalizado en esta actividad.

La siguiente reforma electoral de 1994, producto de los acuerdos de "Barcelona", llevó a un estadio más avanzado a la observación electoral. Esta se extiende, en relación con la observación electoral local, a los actos de preparación de la elección y se incorporan mayores recursos económicos para su realización, involucrando a la Organización de las Naciones Unidas (ONU) en la asignación de los mismos y en el apoyo técnico. Un fenómeno paralelo que produjo estas circunstancias, es la consolidación material de varias organizaciones de observadores electorales.

Por primera vez se admitió la observación electoral extranjera a través de la figura legal de "visitantes extranjeros". La reticencia del gobierno mexicano a su presencia, bajo el principio de "no injerencia” consagrado en el artículo 33 constitucional, es vencida por las exigencias de modernidad derivadas de la firma del Tratado de Libre Comercio con los Estados Unidos de América y Canadá; la incorporación de México a la Organización para la Cooperación y el Desarrollo Económicos (OCDE) y, además, la necesidad del propio gobierno de mostrar la sinceridad de su reforma electoral, así, se argumentó en los círculos políticos más altos del país y frente a los grupos reticentes que, "México no tiene nada que esconder".

En este sentido, la observación electoral nacional y extranjera, empezó a jugar un papel importante en la consolidación del proceso democrático nacional, extendiendo su campo de acción a fenómenos e instituciones que no solo irrumpían el día de la jornada electoral. 
El sistema de nulidades en la materia previsto en la LGSMIME, tiene por objeto general que el proceso electoral sea realizado conforme a las previsiones jurídicas constitucionales y legales, en especial, que el sufragio sea emitido en libertad, mediante elecciones auténticas, equitativas y transparentes.

En los artículos 71 a 78 de la LGSMIME, se establecen las reglas generales, las causales de nulidad de la votación recibida en casilla y los supuestos para anular las elecciones federales.

En realidad, tanto el sistema de medios de impugnación previstos en la ley anteriormente citada como las causales de nulidad de la votación recibida en casilla o de una elección federal, se encuentran dirigidos, el primero, a someter a la autoridad administrativa, partidos, candidatos y ciudadanos a la estricta observancia de las reglas que regulan la contienda electoral, y el segundo, a privar de efectos jurídicos a los actos que el día de la jornada electoral vicien la voluntad ciudadana.

Por lo que respecta al sistema de nulidades en materia electoral, considero que ha dejado de tener eficacia plena debido a la creciente profesionalización del IFE, los métodos altamente vigilados de selección de funcionarios de casilla, la presencia real de los representantes de los partidos en los recintos de votación, y la observación electoral. De esta forma, las irregularidades que se cometían el día de la jornada electoral en las casillas han disminuido enormemente, pasando al terreno del anecdotario popular. Los fraudes electorales "primitivos" que tuvieron en nuestro país denominaciones como "la urna embarazada", "el carrusel", "el ratón loco", "el taco electoral", son más bien cosas del pasado, prácticas en desuso.

Si analizamos el catálogo de nulidades que contempla la LGSMI$\mathrm{ME}$, veremos que su acreditación ante el TEPJF ha ido en franca desaparición, lo que implica, por consecuencia lógica, su abandono como práctica fraudulenta.

Así, es poco común en la práctica electoral encontrar que la casilla se instaló en lugar distinto al señalado por el Consejo Distrital; que se entregaron los paquetes electorales a los consejos fuera de los plazos legales; que se realizó el escrutinio y cómputo de la casilla en local distinto; que se recibió la votación en fecha diversa; que se recibió la votación por personas u órganos distintos a los facultados por el Cofipe; que medió error o dolo en la computación de votos (como esta causal se da con más frecuencia, a partir de la reforma de 2007 se previeron 
Esta revista forma parte del acervo de la Biblioteca Jurídica Virtual del Instituto de Investigaciones Jurídicas de la UNAM

mecanismos para corregir estas anomalías); que se vote sin credencial o que se permita el voto sin estar en la lista nominal de electores; que se impida el acceso o se expulsen injustificadamente a los representantes de los partidos; que se ejerza violencia física o presión sobre los miembros de la mesa directiva de casilla o de los electores, o bien, que se impida votar a los ciudadanos.

Sin embargo, esto no quiere decir que el proceso electoral y la voluntad ciudadana se desarrollen de manera impoluta y se expresen en forma absolutamente legal y libre.

Existen factores sumamente poderosos que se encuentran fuera de la organización propiamente de la elección que influyen o tratan de influir en el resultado de la elección.

Estos poderes fácticos o "salvajes" son los que empañan la autenticidad de la elección: los poderes gubernamentales que condicionan los programas sociales a cambio del voto, los medios de comunicación que favorecen a candidatos y partidos, los empresarios que presionan a sus empleados, los sindicatos que obligan a sus agremiados, los grupos religiosos que utilizan su influencia sobre los feligreses, y sobre todo, la compra del voto; son peligros que obran constantemente sobre la voluntad ciudadana.

Por eso considero que la observación electoral tiene una gran responsabilidad para tratar de evitar este tipo de conductas y prácticas verdaderamente fraudulentas. La actividad de las organizaciones de observadores y la observación individual debe realizarse, como afortunadamente ha venido aconteciendo, fuera de los locales de votación y no exclusivamente el día de la elección.

Las experiencias del pasado proceso electoral demuestran la existencia de la compra del voto, tal práctica debe ser desterrada y castigada. No pasamos desapercibido que para lograr este propósito es necesario un proceso educativo de gran calado por parte de las autoridades, pero estoy seguro que la observación electoral puede incluir en sus tareas, campañas de difusión popular para concientizar al ciudadano del valor de su voto y sobre todo prepararse para la denuncia de esta práctica, especialmente ante la Fiscalía Especializada para la Atención de Delitos Electorales (FEPADE). 


\section{$X$. Nuevos instrumentos jurídicos para el control jurisdiccional ciudadano de los procesos electorales}

En conclusión, considero que el derecho a la observación electoral, como derecho político de participación ciudadana es fundamental y por lo tanto debe elevarse a rango constitucional en los artículos 35 y 41. La corresponsabilidad de los ciudadanos en el proceso a través de la observación electoral, los dotaría de personalidad jurídica que podría producir en el campo jurídico los siguientes efectos:

1) Legitimación para promover acciones jurídicas, en casos concretos, en contra de actos y leyes electorales que vulneren la norma suprema.

2) Legitimación para presentar escritos sobre el proceso electoral con plenos efectos jurídicos.

3) Legitimación para presentar medios de impugnación en materia electoral contra actos ilegales de autoridades y partidos políticos.

Se podría alegar en contra de estas propuestas que una impugnación masiva por parte de los ciudadanos podría abrumar cuantitativamente el proceso judicial haciéndolo inoperante, o que podrían ser utilizados por los partidos derrotados para cuestionar la legitimidad de la elección. Estoy convencido de que estos son alegatos e inconvenientes menores, y que el sistema de justicia en caso de darse una situación parecida, podría procesar sin mayores problemas.

Sin embargo, la ganancia sería enorme para vitalizar, fortalecer y dar efectividad al derecho ciudadano fundamental de participación en la conformación de la representación nacional. No olvidemos que en el campo jurídico, cada vez que ganamos un derecho somos más libres, pues la libertad jurídica es no tener derechos fundados en obligaciones propias.

\section{Fuentes consultadas}

Bodenheimer, Edgar, Teoría del derecho, México, Fondo de Cultura Económica, 1976. 
Esta revista forma parte del acervo de la Biblioteca Jurídica Virtual del Instituto de Investigaciones Jurídicas de la UNAM

Cappelleti, Mauro, La justicia constitucional (estudios de derecho comparado), México, UNAM, Facultad de Derecho, 1987.

García MÁYnez, Eduardo, Positivismo jurídico, realismo sociológico y iusnaturalismo, México, UNAM, 1977.

Recaséns Siches, Luis, Introducción al estudio del derecho, México, Porrua, 1974.

SARtori, Giovanni, ¿Qué es la democracia?, 2a. ed., México, Patria, 1997. 